\title{
ENTRE A MESOPOTÂMIA E O INDUS.
}

Vão sendo determinados os focos iniciais de civilização à medida que os arqueólogos multiplicam as sondagens no terreno e são confrontadas as contribuições trazidas por especialistas de ramos diferentes.

Os sábios concordam em considerar a Mesopotâmia como um dos mais antigos, senão o mais antigo berço da civilização.

Mas com esta questão outras se encadeiam intimamente, tais como a da origem dos sumérios, a da difusão cultural a partir da Mesopotâmia, a das relações entre a Suméria e a bacia do Indus, onde durante a Idade do Bronze floresceu uma brilhante cultura, e muitas mais.

O problema sumério e o do diálogo Sumer-Indus passaram nestes últimos anos a ser vistos a uma luz nova, devido às escavações feitas em ilhas do Gôlfo Pérsico por aqueólogos dinamarqueses.

Já em 1936 Henri Frankfort, a propósito de dois fragmentos de vasos pintados a vermelho ("cerâmica escarlate") desenterrados em Tell Agrab (1) pelos homens da sua expedição, chamou a atenção para as relações culturais entre a Mesopotâmia e a região noroeste da fndia nos começos do Período Dinástico Antigo (c. 3000 a. C.) (pois os cacos remontavam a esta data). Baseou-se para fundamentar a sua hipótese, no fato de se representar num dêles um boi de corcova, de tipo indiano, da espécie que se reproduziu nos carimbos de pedra de Mohenjo Daro (Cultura do Indus), e que não se conhecia então na Mesopotâmia, e no outro, um touro dentro dum recinto retangular, e mulheres nuas batendo em tambores, que Frankfort interpretou como uma cerimônia na qual sacerdotisas prestavam culto ao touro sagrado. Além disso, num dedaço de vaso de esteatite, encontrado na mesma estação, figura também um touro dentro dum recinto ou relicário.

(1). - Tell é o nome aplicado a uma colina artificialmente formada pela acumulação de detritos arqueológtcos. 
Contudo foi necessário esperar até 1953 para que novos e importantes dados viessem enriquecer o problema dos itinerários entre Mesopotâmia e fndia.

As expedições arqueológicas à ilha de Bahrein no Gôlfo Pérsico em 1878 e 1940 tinham apenas explorado alguns túmulos de entre os numerosos que se encontram na ilha (mais de cem mil), muitos dêles remontando à Idade do Cobre (Calcolítica) e à do Bronze. Daí considerar-se Bahrein como uma enorme necrópole da população da Arábia durante o segundo milênio antes da éra cristã. A dada altura, porém, tal explicação não pôde aplicar-se em relação ao espólio duma dessas sepulturas.

Foi por isso que o Dansk Arkaeologisk Bahreinekspedition (Expedição Arqueológica Dinamarquesa de Bahrein), do $\mathrm{Mu}-$ seu Pré-histórico de Aarhus, dirigida por V. Glob partiu em dezembro de 1953 para aquela ilha, tendo, durante cinco meses de investigação, descoberto as ruínas duma cidade, de templos e habitações.

Em face de tais resultados formou-se uma equipe com Glob, o conservador inglês T. Bibby e o arquiteto Kristian Jeppesen, para continuar as escavações em 1955 com a colaboração de Mogens Krustrup e do Dr. Robert Dyson do Museu da Universidade de Pennsylvania.

O financiamento das campanhas arqueológicas ficou a cargo do Fundo de Investigações Científicas do govêrno dinamarquês, da Bahrain Petroleum Company Ltd., do sheik Sulman Al-Khalifah, da Fundação Carlsberg e do Museu da Universidade de Pennsylvania. Sucedem-se várias campanhas tendo em abril de 1957 terminado a quarta.

Resultado das escavações de Bahrein:

I. - Uma cidade em Qala'at-al-Bahrein (costa norte, perto dum forte português arruinado), que teria contado uns 10.000 habitantes.

Talvez devido à forte marinha que garantia as ligações com o continente e à qual estava confiada a defesa da ilha, a cidade não tinha muralhas. Mas à volta de 25,00 a. C. um exército invasor destruiu-a; e a metrópole que se lhe seguiu, aparece já dentro dum impressionante recinto fortificado.

De entre o espólio extraído das ruínas, devem citar-se a cerâmica pintada e os artefatos de silex; tanto na louça como na indústria lítica notam-se afinidade com as da Cultura do Indus. Um carimbo discóide partido, que se encontrou na 


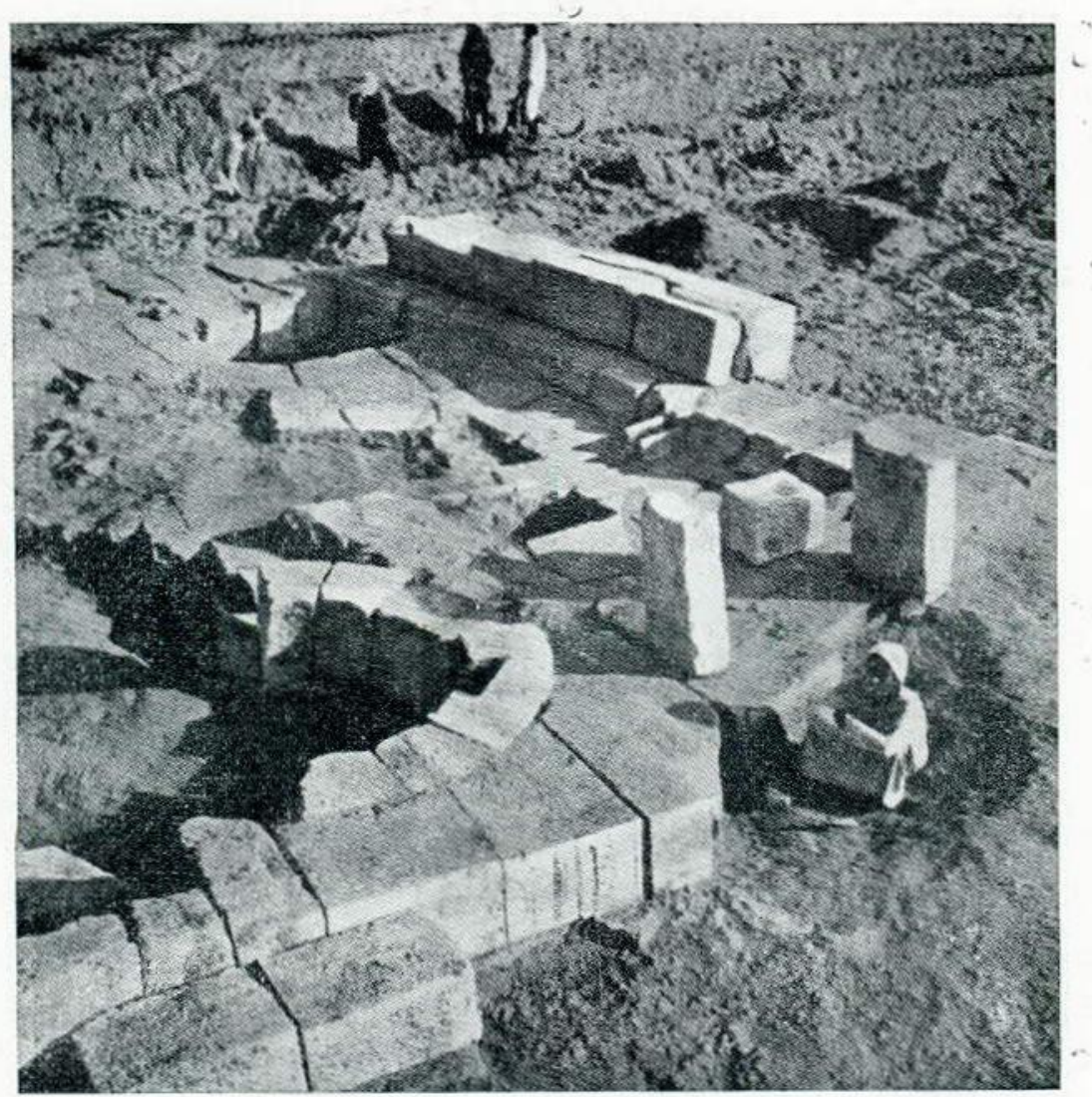

Fig. 1. - Iha Bahrein. Altar do templo III de Barbar que foi destruido por volta de 2500 a. C. As duas construçōes circulares de pedra (das quais se vê uma na gravura) teriam sido revestidas com fôlhas de cobre (Fotografia extraída do "The Illustrated London News", numero de 4 de janeiro de 1958). 


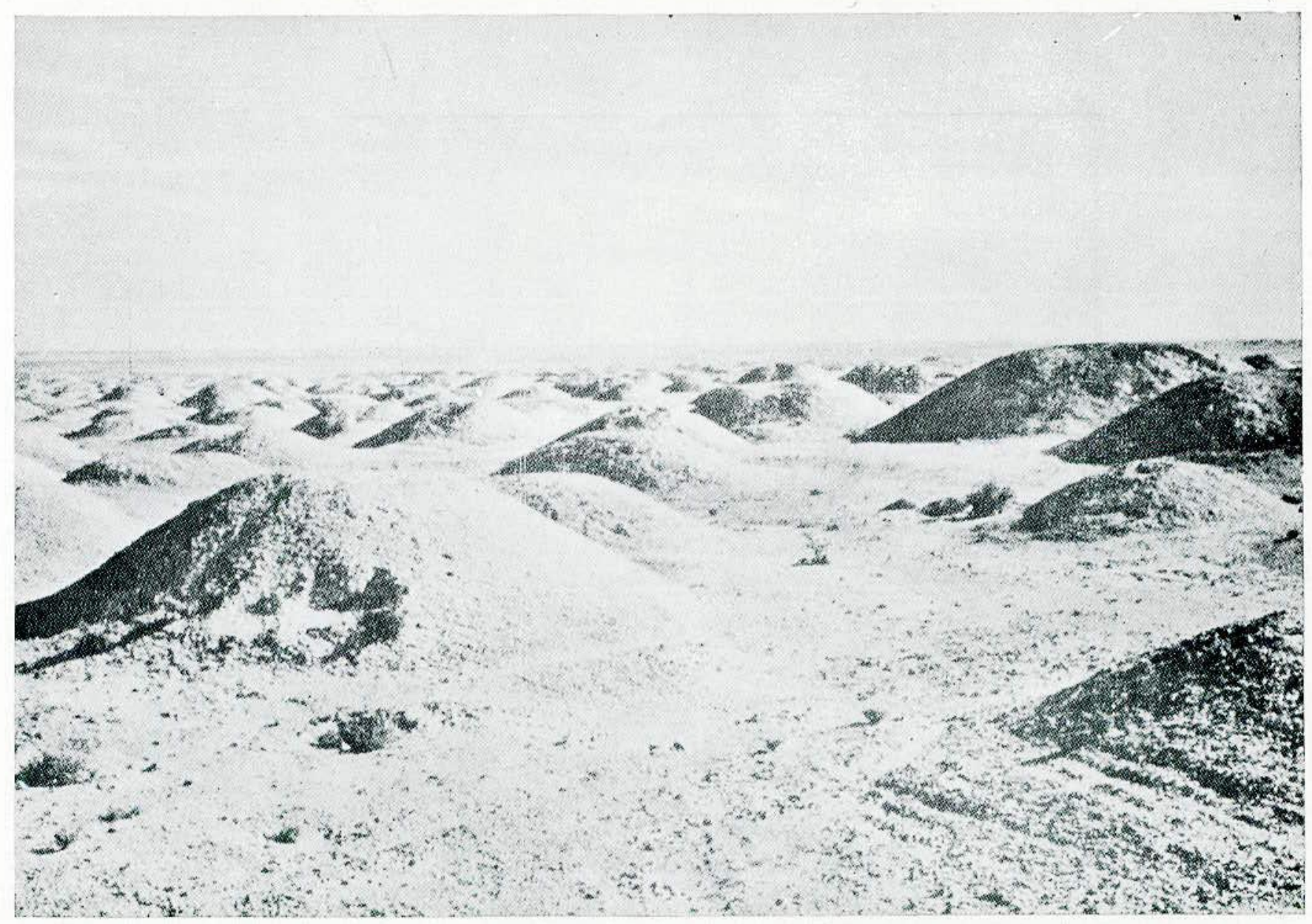

Fig, 2, - Ilha Bahrein. Os 100.000 túmulos na parte setentrional da ilha, (Fotografia extraida de "The Illustrated London News" de 4 de janeiro de 1961) 


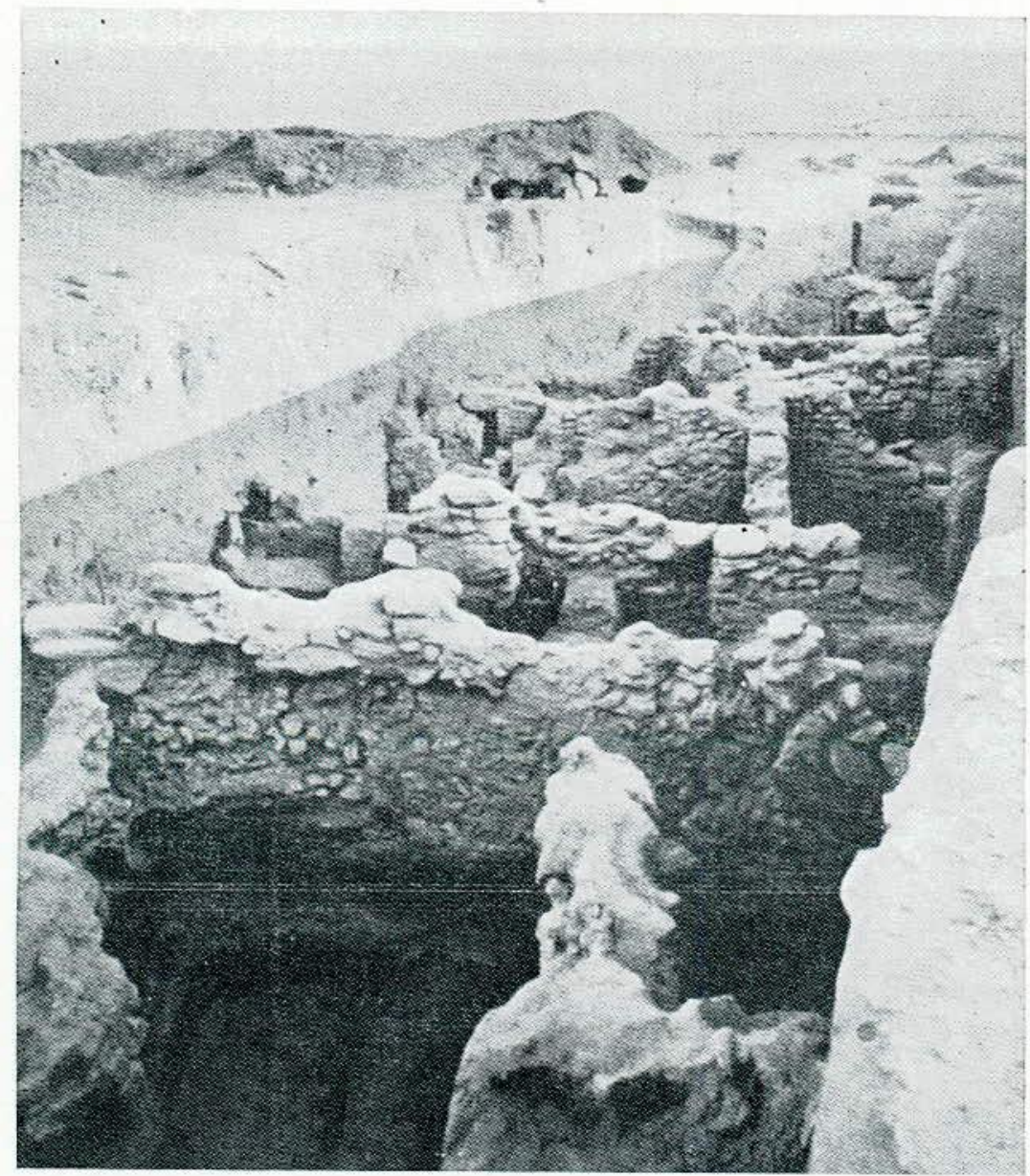

Fig. 3. - Ilha Failaka. As paredes de blocos de coral, rebocadas com argila e estucadas, que pertenceram a casas habitadas há perto de 4.000 anos. (Fotografia extraída de "The Illustrated London News" de 28 de janeiro de 1961). 


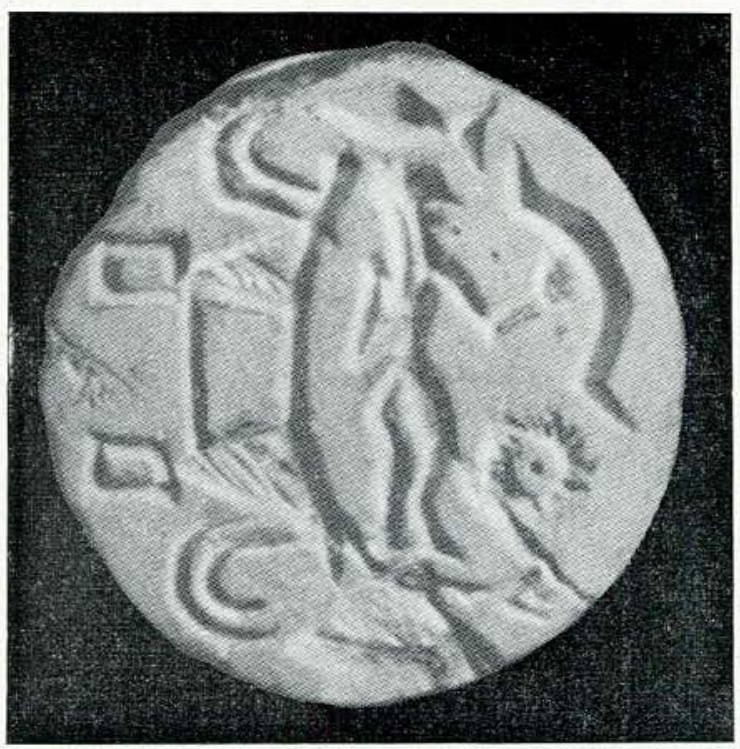

Fig. 4. - Iha Fail-ka. Disco-carimbo. E' de esteatite e representa um homem com escudo e tendo um peixe sôbre a cabeça. As outras imagens insculpidas têm sido interpretadas como representando a ilha com duas cidades (Escala: 3-1). (Fotografia extraida de "The Illustrated London News" de 28 de janeiro de 1961). 


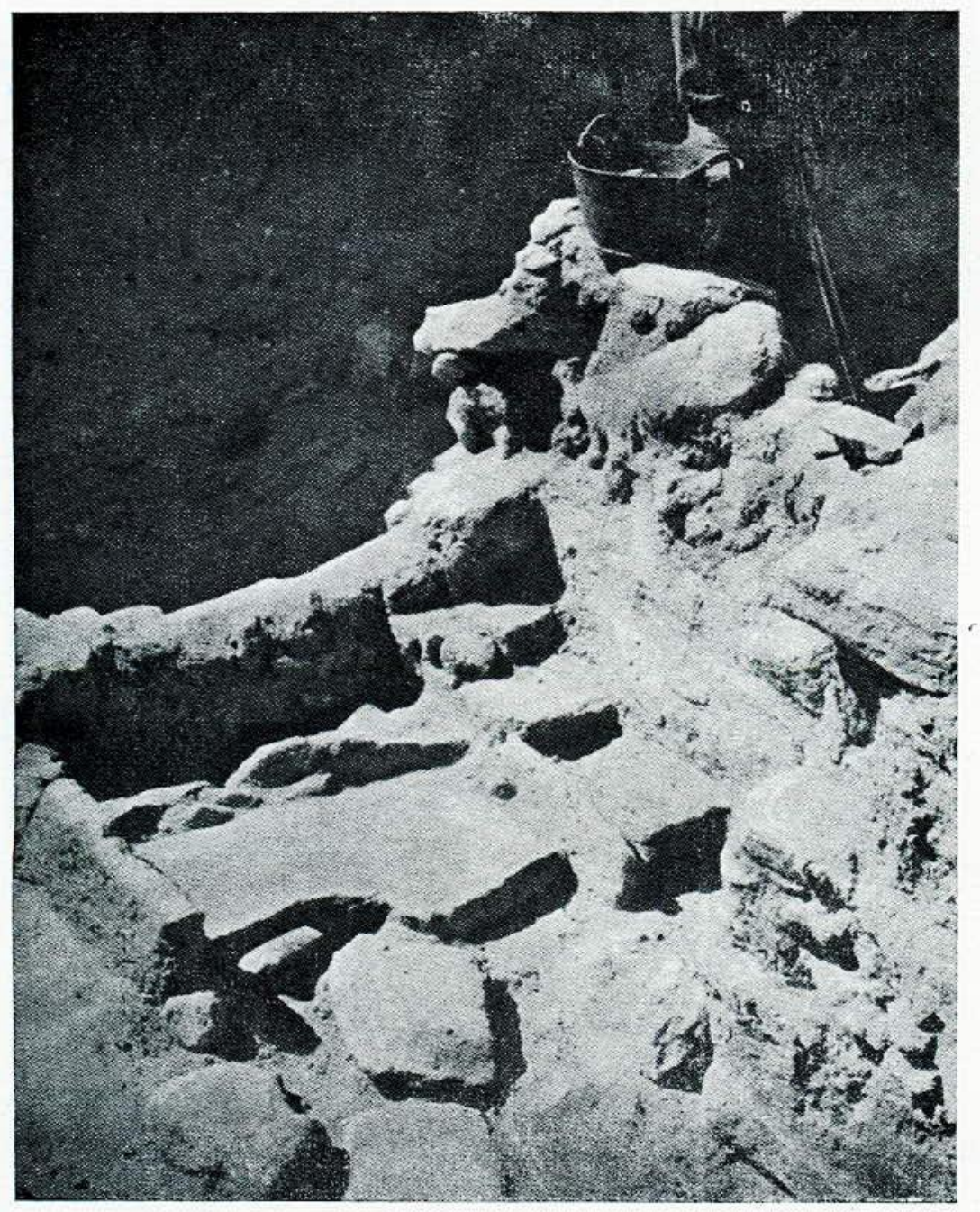

Fig. 5. - Ilha Failaka. A lareira duma das casas de há 4.000 anos. (Fotografia extraída do "The Illustrated London News" de 28 de janeiro de 1961). 
loja dum gravador de pedras, veio a adquirir grande importância e significado ao acharem-se outros em local diferente.

II. - Um templo perto de Diraz, a noroeste da ilha.

Aí descobriram os arqueólogos um corredor em ângulo reto que comunicava com uma câmara subterrânea onde havia uma fonte ladeada por dois bocais de poço talhados cada um num imenso bloco de pedra.

Perto da fonte e no corredor estavam duas estátuas de touro, sem cabeça, ao lado de vasos de pedra. da ilha.

III. - Três templos sobrepostos perto de Barbar ao norte

Todos de tipo semelhante e que foram sucessivamente destruídos (c. 3000 a c. 2500 a. C.).

No mais profundo e mais antigo acharam-se, além de artigos de cobre, vasos de terra-cota do mesmo tipo dos que foram extraídos dos túmulos reais de Ur.

O templo intermédio foi o maior, e pelo aspecto escalonado da sua construção, os arqueólogos concluiram que se tratava de um ziggurat de três pisos. Do espólio aí encontrado, o que tem mais significado para o assunto de que se trata, é uma cabeça de touro, de cobre.

O templo mais recente apresenta como interessante característica as duas construções circulares de pedra que teriam sido revestidas com fôlha de cobre. A frente delas erguia-se um pequeno altar de seç̧ão quadrada, e ao lado duas pedras de altar.

Destas campanhas realizadas em Bahrein, surgiram novos elementos que estão representados ora nas estações da Mesopotâmia, ora nas do Indus, ora numas e noutras simultâneamente.

Em 1958 a expedição arqueológica dinamarquesa, sob a direção de Glob, começou a escavar as colinas arenosas de Failaka, ilha situada na Baía de Kuuait (Kuwait).

Deparou com estreitas paredes de modestas casas e armazéns, feitas de blocos de coral, rebocadas com argila e estucadas, e fêz uma grande colheita de carimbos circulares de esteatite. Recordemos que na cidade arruinada de Bahrein tinha sido achado um carimbo partido do mesmo tipo dos de Failaka. 


\section{CONCLUSÔES.}

\section{1. - As Relações com a fndia.}

As inscrições cuneiformes falam de contactos comerciais com terras que se pensa serem as da bacia do alto Indus e as do litoral do Gôlfo Pérsico. Através dêles viria o lápis lazuli do Pamir; a diorite, a gipsa e o calcário seriam exportados de locais da costa do Gôlfo Pérsico.

Nas inscrições há também notícia duma expedição comercial no Gôlfo Pérsico que durou três anos e regressou a Sumer, com marfim, macacos e pavões. Mas êstes dados da história econômica da Suméria são tardios em relação às provas materiais que forneceram as escavações em Bahrein e Failaka.

De entre as importações recebidas na Mesopotâmia que constam das inscrições, algumas existiam em Bahrein, Failaka e possivelmente noutros pontos do litoral do Irão e da Arábia não ainda descobertos para a arqueologia.

Bahrein como Failaka eram entrepostos onde os carregamentos da Índia e da Arábia eram desembarcados e reexpedidos. Bahrein devia ainda ser procurada devido a contar numerosas fontes nas quais desde por volta de 3000 a. C. iam abastecer-se os marinheiros.

São os túmulos dêstes ricos mercadores intermediários que cobrem a ilha, e em Qala'a ficava um dos seus palácios.

Apresento os elementos comuns às civilizações suméria e industânica proto-histórica encontrados nas duas ilhas:

a). - Cerâmica pintada (Bahrein) idêntica à do Indus.

b). - Indústria e silex (Bahrein) idêntica à do Indus.

c). - Estátuas e cabeças de touro (Bahrein) idênticas às da Suméria, e constituindo indícios dum culto do touro como o que era e é praticado na fndia.

d). - Cerâmica (Bahrein) idêntica à da Dinastia I de Ur.

e). - O tipo arquitetônico do templo II de Barbar (Bahrein) que apresenta certas afinidades com o ziggurat mesopotâmico.

f). - Os dois bocais circulares de poço no templo perto de Diraz (Bahrein), as duas construções circulares de pedra no templo III de Barbar (Bahrein), e os poços existentes em templos da Suméria (por exemplo no de Inanna em Nippur remontando a 2800 a. C.). 
g). - Os copos de barro encontrados na base da elevação (mound) de argila sôbre a qual se construiu o templo I de Barbar (Bahrein, c. 3000 a. C.) que da forma dos que figuram em baixos-relevos e gravuras incisas em placas de pedra dos tempos do Dinástico Antigo, provenientes de cidades sumérias tais como Nippur e Ur.

h). - Dois carimbos cilíndricos da Mesopotâmia e da época de Accad (c. 2400-c. 2200 a. C.) achados em Failaka.

i). - E finalmente a presença dos carimbos circulares de esteatite com imagens incisas em relêvo negativo (insculturas) em Failaka (35 espécimes), em Mohenjo-Daro (Indus) (3 exemplares), na Mesopotâmia (17) e em Bahrein (15). Verifica-se ainda que muitas das figuras humanas insculpidas nos carimbos discoidais são de tipos conhecidos nos carimbos-cilindros da Mesopotâmia, datados da época de Accad. Enquanto na Mesopotâmia predomina o tipo de carimbo cilíndrico, e no Indus os carimbos são quadrangulares; os circulares que aparecem numa região como na outra, seriam produzidos na terra de "Dilman", a que poderá corresponder qualquer das ilhas do Gôlfo Pérsico, talvez Failaka.

\section{2. - A Origem dos Sumérios.}

Era idéia mais ou menos estabelecida que os sumérios tinham vindo duma área ao norte da Mesopotâmia onde havia lagos, talvez da zona onde hoje se encontra a Armênia.

Os próprios sumérios diziam ser oriundos da enigmática "Dilman", a pátria do fabuloso animal cujo corpo tinha uma metade de homem e outra de peixe, e que fôra um "herói de civilização" ao ensinar-lhes o cultivo e a irrigação das terras. Foi em "Dilman" que o único sobrevimente do dilúvio, Xisuthros ou Ziusudra recebera a vida eterna, e foi aí que Gilgamés, outro herói mítico, o foi visitar.

O problema reduz-se pois a estabelecer em bases seguras a localização de "Dilman" que até agora fôra considerada como situada ao norte da terra de Sumer ou Sumir.

Se é ponto assente que as conquistas fundamentais da revolução neolítica (o cultivo e a domesticação) vieram das terras acidentadas ao norte da Mesopotâmia, o povo que nela as introduziu não era o sumério. E' pois admissível, em face dos achados em que se falou, que os sumérios tivessem chegado 
do sul e se instalassem nas terras que uma população mais antiga, vinda do norte, tinha começado a valorizar.

Um nôvo tipo de cerâmica, a invenção da escrita e do cilindro-carimbo, a arquitetura monumental são aspectos que assinalam a presença dos sumérios a partir da época de Uruc, tanto no sul da Mesopotâmia como no Elam (c. 3400-3100 a. C.).

A presença de antigos elementos culturais em ilhas do Gôlfo Pérsico vem dar apôio à viabilidade histórica da legenda de Dilman.

Bahrein situada mais ao sul, teria sido ocupada e civilizada primeiro pelos que seguissem para o setentrião vindo das terras austrais.

Por volta de 2500 a. C. foi arrasada por um povo inimigo, e as relações com a Mesopotâmia cessaram então.

E' na história da Suméria que vamos buscar confirmação para êste fato deduzido pelos arqueólogos do que encontraram em Bahrein.

Efetivamente a partir desta data começa a rarear o lápis lazuli na Mesopotâmia. Esta pedra preciosa que na opinião dos historiadores viria da fndia por via terrestre, e também por via marítima, (tendo em conta a importância das ilhas do Gôlfo Pérsico no tráfico), desapareceu do mercado ou quase, assim que foi cortado o caminho pelo mar.

Um povo diferente do sumério teria então dominado no Gôlfo Pérsico, destruindo bases e feitorias como era Bahrein, e interrompendo as relações entre a Mesopotâmia e as terras a sul e a leste. Talvez se tratasse duma operação militar levada a cabo por semitas, em concordância com a que no norte os tornou senhores da Mesopotâmia (império de Accad).

E' por essa ocasião que começa a desenvolver-se o cen- tro mercantil de Failaka, o que poderia atribuir-se ao fato de ter cessado a talassocracia de Bahrein.

Tal é a hipótese que o estado atual da investigação arqueológica no Oriente Próximo permite arquitetar, e que futuros achados poderão robustecer ou anular. 